Jurnal Kesehatan

Volume 12, Nomor 3, Tahun 2021

ISSN 2086-7751 (Print), ISSN 2548-5695 (Online)

http://ejurnal.poltekkes-tjk.ac.id/index.php/JK

\title{
Bantal Menyusui Memengaruhi Motivasi, Produksi ASI, dan Musculoskeletal Disorder pada Ibu Menyusui
}

\section{Breastfeeding Pillow Affects Motivation, Breastmilk Production, and Musculoskeletal Disorder in Breastfeeding Mothers}

\author{
Yusari Asih \\ Jurusan Kebidanan, Politeknik Kesehatan Tanjung Karang, Indonesia
}

\section{ARTICLE INFO}

\section{Article history}

Received date

05 Oct 2021

Revised date

06 Oct 2021

10 Nov 2021

Accepted date

18 Nov 2021

Keywords:

Breastfeeding pillow;

Breastmilk;

Motivation;

Musculoskeletal disorder.

\section{Kata kunci:}

Bantal menyusui;

ASI;

Motivasi;

Musculoskeletal disorder.

\begin{abstract}
ABSTRAK
Breastfeeding in a sitting position for 30 minutes with the mother's hand supporting the baby causes maternal fatigue. One way to increase motivation, breast milk production and reduce musculoskeletal disorder is by using a breastfeeding pillow. The purpose of this study was to determine the effect of using a breastfeeding pillow on motivation, milk production, and musculoskeletal disorder of breastfeeding mothers in the Pringsewu Regency in 2020. This study is a quasi-research. experiment with post-test design with control group design. The sampling technique was purposive sampling, the number of samples was 48 breastfeeding mothers $0-1$ months. The intervention group used a redesigned breastfeeding pillow, the control group used a regular breastfeeding pillow. The data were processed with univariate (mean) and bivariate analysis with Independent T-Test and Hotelling T-Test. The results showed that on average the respondents had the motivation to breastfeed in the high category, breast milk production in the good category, and musculoskeletal disorder in the not sick category. There were significant differences in motivation for breastfeeding, milk production, and musculoskeletal disorders between the group of mothers who used the redesigned breastfeeding pillow and the group that used the regular breastfeeding pillow. To midwives to promote the use of redesigned breastfeeding pillows to help increase motivation, milk production, and breastfeeding comfort so that musculoskeletal disorders do not occur and researchers can conduct further research with other variables that can affect motivation, milk production, and musculoskeletal disorders in breastfeeding mothers.
\end{abstract}

Pemberian ASI dengan posisi duduk, selama 30 menit dengan posisi tangan ibu menyangga bayi menyebabkan kelelahan ibu. Salah satu cara untuk meningkatkan motivasi, produksi ASI dan menurunkan musculoskeletal disorder adalah dengan penggunaan bantal menyusui. Tujuan penelitian untuk mengetahui pengaruh penggunaan bantal menyusui terhadap motivasi, produksi ASI dan musculoskeletal disorder ibu menyusui di Kabupaten Pringsewu tahun 2020. Penelitian ini merupakan penelitian quasi eksperimen dengan desain post test with control group design. Teknik pengambilan sampel purposive sampling, jumlah sampel sebanyak 48 ibu menyusui 0-1 bulan. Kelompok intervensi menggunakan bantal menyusui re-desain, kelompok kontrol yang menggunakan bantal menyusui biasa. Data dianalisis secara univariat (mean) dan bivariat dengan Independent $T$ Test serta Hotelling $T$ Test. Hasil menunjukan rerata responden memiliki motivasi pemberian ASI dalam kategori tinggi, produksi ASI dalam kategori baik dan musculoskeletal disorder dalam kategori tidak sakit. Ada perbedaan yang signifikan motivasi pemberian ASI, produksi ASI dan musculoskeletal disorder antara kelompok ibu yang menggunakan bantal menyusui re-desain dengan kelompok yang menggunakan bantal menyusui biasa. Kepada bidan untuk mempromosikan penggunaan bantal menyusui re-desain untuk membantu meningkatkan motivasi, produksi ASI dan kenyamanan menyusui sehingga tidak terjadi musculoskeletal disorder serta peneliti dapat melakukan penelitian lebih lanjut dengan variabel yang lain yang dapat berpengaruh pada motivasi, produksi ASI dan musculoskeletal disorder pada ibu menyusui.

\section{Corresponding Author:}

Yusari Asih

Jurusan Kebidanan, Politeknik Kesehatan Tanjungkarang, Indonesia

Email: yusariasih@poltekkes.tjk.ac.id 


\section{PENDAHULUAN}

Menyusui merupakan aktivitas yang sangat penting bagi ibu dan bayi. Dalam proses menyusui terjadi hubungan yang erat dan dekat antara ibu dan bayi. Ibu menyusui melakukan pekerjaan rutin untuk bayi pada enam bulan pertama. Pemberian ASI dalam enam bulan pertama tertuang pada Peraturan Pemerintah Republik Indonesia Nomor 33 Tahun 2012, tentang Pemberian Air Susu Ibu secara Eksklusif (Presiden Republik Indonesia, 2012).

Isu-isu ergonomi kesehatan semakin banyak diminati, mengingat setiap aktivitas kehidupan, mulai dari bangun tidur hingga istirahat pada semua orang akan melibatkan kerja tubuh. Kegiatan yang dilakukan secara rutinitas setiap hari akan berpotensi menimbulkan kelelahan ataupun keluhan musculoskeletal, jika aktivitas tidak dijalankan secara ergonomis, termasuk kegiatan menyusui pada ibu post partum.

Dari delapan aspek ergonomi, gizi, pemanfaatan tenaga otot, sikap kerja, kondisi lingkungan, kondisi waktu, kondisisosial, kondisi informasi dan interaksi manusia-mesin (Adiatmika et al., 2007), tiga aspek yang sangat kuat yang dikaji sangat memengaruhi keberhasilan ibu untuk menyusui bayi yaitu ibu menyusui memerlukan tambahan nutrisi dalam melaksanakan peran saat menyusui karena asupan gizi yang seimbang meningkatkan produksi ASI. Ibu menyusui memerlukan tambahan kebutuhan energi sebesar 800kalori/hari pada 6 bulan pertama. Enam bulan selanjutnya 500 kalori/hari (Asih \& Nyimas, 2020), pengasuhan yang dilakukan ibu pada bayi memerlukan kekuatan fisik dan psikis, karena bayi memerlukan pengasuhan terus menerus selama 24 jam setiap harinya, Sikap ibu saat menyusui dapat menyebabkan kelelahan, sikap menyusui yang benarsangat menguntungkan bagi ibu dan bayi (Purnomo, et al., 2007).

Faktor terpenting bagi keberhasilan menyusui adalah kenyamanan saat menyusui, termasuk posisi dan cara ibu saat menyusui. Pemberian ASI dengan posisi duduk, dengan lama pemberian ASI 30 menit serta posisi tangan ibu yang menyangga bayi menyebabkan kelelahanibu saat menyusui bayi. Sebagian besar waktu ibu post partum akan digunakan untuk menyusui bayinya, baik siang dan malam hari selama beberapa bulan.

Keberhasilan menyusui dipengaruhi ole usia ibu, pendidikan, pekerjaan dan motivasi ibu untuk menyusui. Motivasi adalah hasil dari kumpulan kekuatan internal dan eksternal yang menyebabkan orang memilih jalan untuk bertindak yang sesuai dan menggunakan prilaku tertentu (Nisman, et al., 2020) . Motivasi seorang ibu dalam menyusui bayi dapat dari dalam diri yang berupa kesadaran dan kemauan maupun dari luar yaitu dorongan keluarga, masyarakat dan tenaga kesehatan, yang berupa pemberian informasi. Ibu dengan motivasi rendah cenderung tidak memberikan ASI karena kurangnya motivasi dari dalam diri maupun dari luar. Sedangkan ibu yang memiliki motivasi tinggi, sebagian besar memberikan ASI secara eksklusif karena ibu sadar akan manfaat dan keuntungan ASI bagi ibu maupun bayi, selain itu tersedianya sarana dalam menyusui akan mendorong ibu untuk menyusui secara eksklusif. Ketepatan posisi bayi pada saat menyusu merupakan sesuatu yang penting untuk keberhasilan ibu dalam memberikan ASI pada bayinya. Mengatur posisi saat bayi menyusu sangat berkaitan dengan bayi dapat bayi dapat menyusu dengan baik, sehingga ASI yang keluar sesuai dengan yang kebutuhan bayi. Banyaknya ASI yang keluar tergantung dari seberapa banyak isapan bayi dan seberapa banyak yang dapat bayi keluarkan (Amir, et al., 2020).

Selama kegiatan menyusui, ibu dan bayi pada posisi tetap dan dalam waktu agar proses menyusui dapat berjalan lancar. Ibu dalam posisi tetap selama 20-30 menit. Permasalahan yang terjadi pada ibu post partum adalah permasalahan terkait proses setelah persalinan dan aktivitas menyusui.

Aktivitas menyusui yang dilakukan berulang-ulang dari hari kehari sangat rentan bagi ibu mengalami kelelahan dan keluhan musculoskeletal. Kelelahan dan keluhan musculoskeletal ini dapat terjadi tidak saja pada jenis pekerjaan yang dilakukan berulang tetapi ada faktor lain yang dapat menyebabkannya, seperti cara kerja, kondisi kerja dan peralatan yang tidak ergonomis Kelelahan dan keluhan musculoskeletal yang berkepanjangan, dan akan membuat kesulitan bagi ibu dalam merawat bayi.

Hasil penelitian Amalia, 2018, didapatkan bahwa ada hubungan yang signifikan antara dukungan sarana dengan keberhasilan pemberian ASI eksklusif dengan nilai $p$-value $=0,008$. Ketersediaan sarana dan prasarana pendukung untuk memberikan ASI eksklusif berupa ASI perah bagi ibu bekerja sangat menunjang keberhasilan pemberian ASI eksklusif. Meskipun demikian, masih terdapat ibu bekerja yang lebih memilih memberikan susu formula dengan alasan kepraktisan dalam penyimpanan maupun pemberiannya. Tersedianya fasilitas berupa ruang laktasi merupakan faktor yang sangat penting dalam mendukung keberhasilan pemberian ASI 
eksklusif (Amalia \& Rizki, 2018), hasil penelitian didapatkan bahwa ada hubungan yang signifikan antara dukungan sarana dengan keberhasilan pemberian ASI eksklusif dengan nilai $p$-value $=0,008$. Ketersediaan sarana dan prasarana pendukung untuk memberikan ASI eksklusif berupa ASI perah bagi ibu bekerja sangat menunjang keberhasilan pemberian ASI eksklusif. Meskipun demikian, masih terdapat ibu bekerja yang lebih memilih memberikan susu formula dengan alasan kepraktisan dalam penyimpanan maupun pemberiannya. Tersedianya fasilitas berupa ruang laktasi merupakan faktor yang sangat penting dalam mendukung keberhasilan pemberian ASI eksklusif (Santiana, et al., 2017).

Berdasarkan hasil wawancara pada ibu menyusui dalam posisi duduk di kursi di RSU Mitra Husada Pringsewu, didapat hasil: dari 10 orang responden, menyatakan adanya keluhan pada musculoskeletal sebanyak $70 \%$ (7 orang). Dengan rincian keluhan berdasarkan areal tubuh sebagai berikut : pada bagian leher sebesar $70 \%$, bagian bahu sebesar $70 \%$, pada lengan atas dan bawah sebesar $70 \%$, bagian punggung sebesar $80 \%$, bagian pinggang sebesar $70 \%$, pada kaki dan tumit sebesar 3\%. Keluhan terhadap kelelahan didapat hasil: dari 10 orang responden ibu mengalami kelelahan berat sebesar $60 \%$. Meskipun tingkat kelelahan relatif ringan jika terjadi berulang-ulang berakibat pada kelelahan kronis yang mampu mengurangi kapasitas kerja dan ketahanan tubuh.

Cara dan lama menyusui bayi yang menyebabkan kelelahan pada ibu menyusui, ketegangan otot bahu serta rasa pegal/ kaku, bahkan nyeri pada bahu terjadi bila kondisi ini berlangsung terus- menerus. Permasalahan kelelahan terjadi pada ibu, selain karena cara dan lama menyusui juga karena tidak adanya alat bantu saat ibu menyusui, sehingga akhirnya ibu hanya mengandalkan anggota tubuhnya untuk menopang tubuh bayi saat menyusui, saat ini diperlukan alat bantu yang ergonomis ketika ibu menyusui bayi.

Penelitian sejenis pernah dilakukan oleh Prihantara (2012), terhadap ibu yang pertama kali menyusui menunjukkan bahwa ibu yang pertama kali menyusui mempunyai keluhan subjektif: tangan terasa pegal saat menopang bayi, punggung sakit akibat menbungkuk, badan terasa lelah akibat mengendong bayi, susah memposisikan mulut bayi dengan puting, bayi sering menangis akibat posisi tidak nyaman, ASI tidak keluar.

Menurut BorgStein dan Dugan (2007; dalam Roberts, 2011) setelah dilakukan pengestimasian secara virtual kepada seluruh ibu menyusui, sakit pada punggung adalah kejadian paling umum yang dikeluhkan oleh ibu menyusui dengan persentasi sebesar $50 \%$, untuk permasalahan ibu menyusui ini diperlukan alat bantu, kondisi menyusui yang nyaman bagi ibu dan bayi akan meningkatkan keberhasilan pada proses menyusui. Dengan menggunakan alat bantu menyusui yang ergonomis akan mampu membuat rasa nyaman saat menyusui, baik ibu maupun bayi, sehingga memberikan manfaat saat menyusui bayi. Alat bantu yang ada belum maksimal saat digunakannya dimana posisi lengan ibu masih tergantung saat menyusui, jika lama menyusui 20-30 menit, maka ada tahanan beban pada lengan selama ini, kondisi ini menyebabkan keluhan rasa lelah pada ibu.

Oleh karena itu perlu dilakukan rancangan perbaikan pada bantal menyusui yang ada dipasaran. Rancangan perbaikan bantal menyusui dibuat dengan mempertimbangkan hasil pengukuran antropometri. Antropemetri adalah ilmu yang berkaitan dengan pengukuran dimensi dan cara untuk mengaplikasikan karakteristik tertentu untuk tubuh manusia (Roebuck, 1994 dalam Wardani, 2003).

Pengukuran dimensi tubuh ini bertujuan untuk memberikan posisi yang nyaman saat ibu menyusui. Dari 10 orang ibu menyusui dengan posisi duduk menggunakan bantal tidur biasa, dimana tinggi badan ibu menyusui antara $150 \mathrm{~cm}$ sampai dengan $160 \mathrm{~cm}$, ibu merasa nyaman menyusui dengan penambahan ukuran tinggi bantal sekitar $10 \mathrm{~cm}$ sehingga tinggi bantal secara keseluruhan $22 \mathrm{~cm}$. Berdasarkan uraian tersebut di atas dipandang perlu dilakukan evaluasi penggunaan re-desain bantal menyusui agar sesuai dengan kaidah-kaidah ergonomi sehingga faktor risiko akibat posisi yang tidak ergonomi selama menyusui dapat berkurang.

\section{METODE}

Penelitian ini menggunakan metode quasi experiment (eksperimen semu). Desain penelitian yang digunakan dalam penelitian ini adalah "Nonequivalent Control Group Design". Di dalam desain ini, penelitian menggunakan satu kelompok eksperimen dengan kelompok pembanding dengan diawali dengan sebuah tes awal (pretest) yang diberikan kepada kedua kelompok, kemudian diberi perlakuan (treatment). Penelitian kemudian diakhiri dengan sebuah tes akhir (post-test) yang diberikan kepada kedua kelompok.

Penelitian ini dilaksanakan mulai Maret s.d Desember 2020 di PMB di Kabupaten 
Pringsewu. Populasi target dari penelitian ini adalah semua ibu menyusui dengan usia bayi 0-1 bulan di Kabupaten Pringsewu Tahun 2020.

Jumlah sampel 48 ibu menyusui bayi $0-3$ bulan di wilayah kabupaten Pringsewu, 24 kelompok pengguna bantal menyusui re-desain dan 24 kelompok kontrol. diambil dengan purposive sampling. Bantal menyusui re-desain yang digunakan dalam penelitian ini diproduksi secara terstandar dengan memperhatikan antopometri ibu. Motivasi dan produksi ASI diukur dengan menggunakan kuesioner

Kriteria inklusi ibu menyusui $0-3$ bulan di Kabupaten Pringsewu tahun 2020, tidak menerima pengobatan tertentu, tidak mengalami masalah kesehatan/kecacatan, bayi lahir sehat dan bugar, dan ibu/keluarga bersedia mengisi informed consent. Kriteria eksklusi Ibu menyusui bayi kembar, bayi prematur atau bayi kecil masa kehamilan, memiliki komplikasi kehamilan dan persalinan, bayi yang dilahirkan dengan cacat / komplikasi/ kelainan struktural.

Penelitian ini telah melewati kaji etik dan mendapatkan Keterangan Layak Etik dari Komite Etik Penelitian Kesehatan Politeknik Kesehatan Tanjung Karang Nomor 263/KEPK-TJK/V/2020.

\section{HASIL}

Data penelitian terdiri dari motivasi, produksi ASI, dan musculoskeletal disorder diukur setelah kelompok mendapat intervensi penggunaan bantal menyusui re-desain pada kelompok intervensi dan penggunaan bantal menyusui biasa pada kelompok kontrol.

\section{Tabel 1. Karakteristik Responden}

\begin{tabular}{lrr}
\hline \multicolumn{1}{c}{ Variabel } & Jumlah & \% \\
\hline Umur & & \\
20-35 tahun & 40 & 83,3 \\
$\quad<20$ tahun atau > 35 th & 8 & 16,7 \\
Paritas & & \\
$\quad$ Multipara & 22 & 45,8 \\
$\quad$ Primipara & 26 & 54,2 \\
Pendidikan & & \\
$\quad$ SMA dan Perguruan Tinggi & 32 & 66,7 \\
$\quad$ Tidak Sekolah, SD, SMP & 16 & 33,3 \\
Pekerjaan & & \\
$\quad$ Tidak Bekerja & 29 & 60,4 \\
$\quad$ Bekerja & 19 & 39,6 \\
Pendapatan Keluarga & & \\
$\quad$ Z UMR Pringsewu & 31 & 64,6 \\
$\quad$ < UMR Pringsewu & 17 & 35,4 \\
\hline
\end{tabular}

Berdasarkan tabel 1 dapat diketahui bahwa mayoritas responden berumur dalam kurun reproduksi sehat yaitu 20-35 tahun sebesar
$83.3 \%$, sebagian besar primipara $(54,21 \%)$, sebagian besar berpendidikan SMA dan Perguruan Tinggi (66,7\%), sebagian besar tidak bekerja $(60,4 \%)$, dan berpenghasilan lebih besar dari UMR Pringsewu $(64,6 \%)$.

Tabel 2. Distribusi Responden Berdasarkan Motivasi Pemberian ASI, Produksi ASI, dan Musculoskeletal Disorder

\begin{tabular}{lrc}
\hline \multicolumn{1}{c}{ Variabel } & Jumlah & \% \\
\hline Motivasi Pemberian ASI & & \\
$\quad$ Tinggi & 31 & 64,6 \\
$\quad$ Rendah & 17 & 35,4 \\
Produksi ASI & & \\
$\quad$ Baik & 31 & 64,6 \\
$\quad$ Kurang & 17 & 35,4 \\
Musculoskeletal Disorder & & \\
$\quad$ Tidak Sakit & 19 & 39,6 \\
$\quad$ Cukup Sakit & 17 & 35,4 \\
$\quad$ Sakit & 6 & 12,5 \\
$\quad$ Sangat Sakit & 6 & 12,5 \\
\hline & & \\
\hline
\end{tabular}

Berdasarkan tabel 2 dapat diketahui bahwa sebagian besar motivasi dan produksi ASI responden dalam kategori baik yaitu sebesar $64,6 \%$, dan keluhan musculoskeletal disorder dalam kategori tidak sakit sebesar 39,6\%.

\section{Tabel 3. Pengaruh Pnggunaan Bantal Menyusui terhadap Motivasi Pemberian ASI}

\begin{tabular}{lrrrr}
\hline \multicolumn{1}{c}{ Intervensi } & Mean & SD & SE & p-value \\
\hline $\begin{array}{l}\text { Bantal Menyusui } \\
\text { Reedsain }\end{array}$ & 1,58 & 0,504 & 0,103 & 0,001 \\
$\begin{array}{l}\text { Bantal Menyusui } \\
\text { Biasa }\end{array}$ & 1,12 & 0,338 & 0,069 & \\
\hline
\end{tabular}

Berdasarkan Tabel 3 diketahui bahwa rerata Motivasi pemberian ASI pada ibu yang menggunakan bantal menyusui re- desain adalah 1,58 dengan standar deviasi 0,504, sedangkan ibu yang menggunakan bantal menyusui biasa rerata Motivasi pemberian ASInya adalah 1,12 dengan standar deviasi 0,338. Hasil uji statistik didapatkan nilai $\mathrm{p}=0,001$, berarti pada alpha $5 \%$ terlihat ada perbedaan yang signifikan rerata Motivasi pemberian ASI antara ibu yang menggunakan bantal menyusui re-desain dengan ibu yangmenggunakan bantal menyusui biasa.

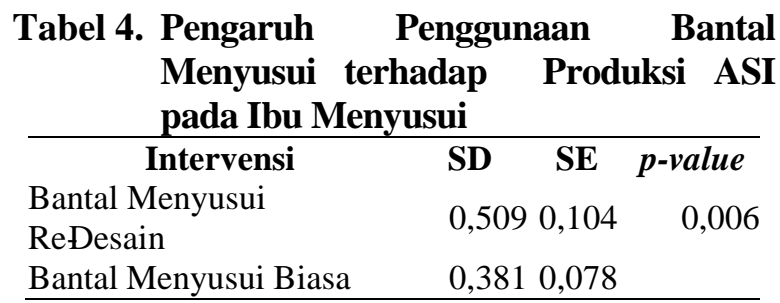


Pada Tabel 4 nilai rerata Produksi ASI pada ibu yang menggunakan bantal menyusui redesain adalah 1,54 dengan standar deviasi 0,104, sedangkan ibu yang menggunakan bantal menyusui biasa rerata produksi ASInya adalah 1,17 dengan standar deviasi 0,078 . Hasil uji statistik didapatkan nilai $p$-value $=0,006$, berarti pada alpha $5 \%$ terlihat ada perbedaan yang signifikan rerata Produksi ASI antara ibu yang menggunakan bantal menyusui re-desain dengan ibu yang menggunakanbantal menyusui biasa.

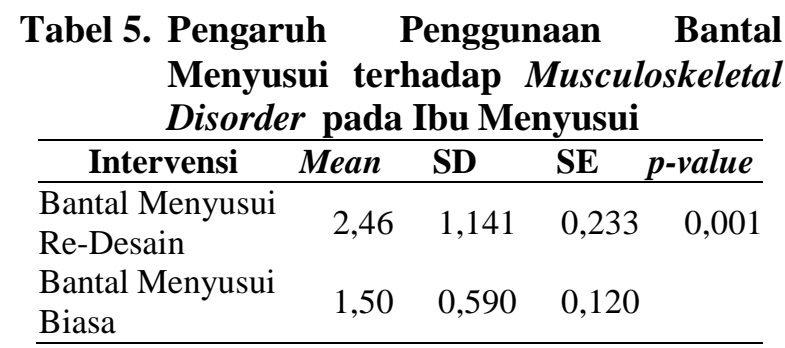

Pada Tabel 5 nilai rerata Produksi ASI pada ibu yang menggunakan bantal menyusui redesain adalah 2.46 dengan standar deviasi 1,141, sedangkan ibu yang menggunakan bantal menyusui biasa rerata produksi ASInya adalah1.50 dengan standar deviasi 0,590. Hasil uji statistik didapatkan nilai $p$-value $=0,001$, berarti pada alpha 5\% terlihat ada perbedaan yang signifikan rerata musculoskeletal disorder antara ibu yang menggunakan bantal menyusui re-desain dengan ibu yang menggunakan bantal menyusui biasa.

Tabel 6. Multivariat test Hotteling's Trace

\begin{tabular}{|c|c|c|c|}
\hline \multicolumn{2}{|c|}{$\begin{array}{c}\text { Descriptive Statistic } \\
\text { Penggunaan Bantal Menyusui }\end{array}$} & Mean & $\begin{array}{c}\text { Std. } \\
\text { Deviation }\end{array}$ \\
\hline \multirow{3}{*}{$\begin{array}{l}\text { Motivasi } \\
\text { Pemberian ASI }\end{array}$} & $\begin{array}{l}\text { Bantal Menyusui } \\
\text { Re-desain }\end{array}$ & 1,58 & 0,504 \\
\hline & $\begin{array}{l}\text { Bantal Menyusui } \\
\text { Biasa }\end{array}$ & 1,13 & 0,338 \\
\hline & Total & 1,35 & 0,483 \\
\hline \multirow{3}{*}{ Produksi ASI } & $\begin{array}{l}\text { Bantal Menyusui } \\
\text { Re-desain }\end{array}$ & 1,54 & 0,509 \\
\hline & $\begin{array}{l}\text { Bantal Menyusui } \\
\text { Biasa }\end{array}$ & 1,17 & 0,381 \\
\hline & Total & 1,35 & 0,483 \\
\hline \multirow{3}{*}{\multicolumn{2}{|c|}{$\begin{array}{lc} & \text { Bantal Menyusui } \\
\text { Keluhan } & \text { Re-desain } \\
\text { MusculoskeletalBantal Menyusui } \\
\text { Disorder } & \text { Biasa }\end{array}$}} & 2,46 & 1,141 \\
\hline & & 1,50 & 0,590 \\
\hline & & 1,98 & 1,021 \\
\hline
\end{tabular}

Berdasarkan tabel 6 dapat diketahui bahwa rerata motivasi pemberian ASI, produksi ASI dan Musculoskeletal disorder pada ibu yang menyusui dengan bantal menyusui re-desain lebih tinggi daripada ibu yang menyusui dengan menggunakan bantal menyusui biasa.

\section{PEMBAHASAN}

\section{Karakteristik Responden}

Responden dalam penelitian ini sebagian besar adalah primipara (melahirkan anak pertama). Pada primipara pengalaman persalinan dan menyusui merupakan pengalaman pertama yang sangat menegangkan dan merupakan sumber kecemasan. Ibu yang belum pernah menyusui (primipara) akan mempunyai produksi ASI yang lebih sedikit dibanding ibu yang pernah menyusui. Hasil penelitian ini belum dilakukan dengan mengantisipasi variabel pengganggu tersebut.

Karakteristik umur responden dalam penelitian ini sebagian besar berusia 20- 35 tahun yang merupakan kurun umur reproduksi sehat. Umur merupakan salah satu faktor yang dapat memengaruhi produksi dan kelancaran ASI. Ibu yang umurnya lebih muda akan lebih banyak mmeproduksi ASI dibandingkan ibu yang umurnya lebihtua. Hasil penelitian menunjukkan bahwa umur memengaruhi kelancaran dan lama waktu pengeluaran ASI. Semakin ibu berumur berisiko tinggi yaitu $>35$ tahun, produksi ASI bertambah banyak. Rentangan umur yang aman untuk melahirkan, menurut Grandjean (1997), umur akan berpengaruh terhadap kemampuan kerja fisik atau kekuatan otot, dimana kemampuan fisik maksimal baik laki- laki maupun perempuan akan semakin menurun seiring dengan bertambahnya umur.

Kemampuan fisik maksimal akandicapai pada umur antara 25 sampai dengan 35 tahun. Umur 21-35 tahun adalah umur yang paling ideal untuk menyusui, resiko terjadinya gangguan kesehatan yang dialami oleh ibu sangat rendah, dan perkembangan tingkat kematangan ibu sudah lebih matang pada umur ini, dimana pada umur ini memiliki tingkat kematangan reproduksi, tingkat emosional, atau bahkan aspek sosial. Menurut Manuaba (1998) kehamilan pada umur di bawah 20 tahun mempunyai risiko: (1) Anemia; (2) Gangguan tumbuh kembang janin; (3) Keguguran, prematuritas, atau BBLR; (4) Gangguan persalinan; (5) Preeklampsi; (6) Perdarahan antepartum. Kematian maternal pada umur di bawah 20 tahun dua sampai lima kali lebih tinggi dari pada umur 20 sampai 29 tahun. (Prawiroharjo, 2008).

Pendidikan merupakan variabel tidak langsung yang bisa memengaruhi motivasi dan perilaku ibu dalam mempersiapkan ASI sejak dalam kehamilan. Namun dalam penelitian ini pendidikan tidak memengaruhi motivasi dan produksi ASI. Hal ini sesuai dengan penelitian 
yang dilakukan oleh Moore dan Coty (2006) yang menunjukkan bahwa keberhasilan menyusui tidakditentukan oleh tingkat pendidikan ibu akan tetapi oleh informasi yang diterima saat prenatal.

Status pekerjaan dalam penelitianini tidak memengaruhi motivasi dan produksi ASI. Pendapat mengenai ibu bekerja akan lebih banyak informasi harus dilihat dari pekerjaan ibu tersebut, apakah informasi yang didapat mengenai perawatan kehamilan dan persiapan menyusui ataukah hal yang lain.

Teori yang dikemukakan oleh Bobak (2005), perangsangan hormon oksitosin ada beberapa macam, diantaranya pijat oksitosin, hypnobreastfeeding dan lain-lain. Hypnobreastfeeding dalam penelitian ini terbukti memengaruhi motivasi dan produksi ASI. Hasil penelitian ini berbeda dengan penelitian yang dilakukan Asih (2020) yang menyatakan bahwa hypnobreastfeeding dapat memengaruhi waktu pengeluaran ASI.

Antropometri subjek yang diukur meliputi tinggi badan ibu, tinggi siku pada posisi istirahat, rentang dari siku ke siku. Pengukuran antropometri subjek tersebut berkaitan dengan alat yang akan dirancang yaitu desain bantal menyusui yang baru bagi ibu menyusui. rerata data antropometri subjek pada kelompok kontrol dalam penelitian ini adalah tinggi badan ibu $155,64 \mathrm{~cm} \pm 2,618$, tinggi siku pada posisi duduk $21,18 \mathrm{~cm} \pm 1,250$ dan rentang dari siku ke siku $41,36 \mathrm{~cm} \pm 1,286$. Sedangkan kelompok perlakuan : tinggi badan $157,64 \mathrm{~cm} \pm 4,567$, tinggi siku pada posisi duduk $21,73 \mathrm{~cm} \pm 1,421$ dan rentang dari siku ke siku 42,45cm $\pm 1,508$.

Rerata tinggi siku pada posisi istirahat/duduk sebesar $22 \mathrm{~cm}$ dipakai untuk menentukan desain tinggi bantal menyusui yang baru, dalam penelitian ini ditetapkan pada persentil 50, berdasarkan pengukuran lainnya maka desain lebar bantal yang diambil dari dimensi rentang dari siku ke siku sebesar $50 \mathrm{~cm}$ pada pesentil 95, tujuan penggunaan nilai persentil 95 adalah agar pada postur ibu yang lebih besar dapat menggunakan bantal ini. Berdasarkan pengamatan dan analisis terhadap ibu menyusui baik yang menggunakan bantal menyusui yang lama maupun menggunakan bantal yangsudah diredesain, anggota gerak yang paling banyak digunakan adalah bagian tubuh atas yang digunakan merangkul dan memegang bayi sehingga tinggi bantal yang dirancang $22 \mathrm{~cm}$ dan lebar bantal dirancang $50 \mathrm{~cm}$.

Penelitian yang melibatkan tinggi siku duduk dalam perancangan bantal menyusui dapat dilihat pada hasil penelitian Prihantara (2012) yang melaporkan lebar bantal bayi dirancang berdasarkan rentang siku ke siku, berdasarkan analisa ergonomi diperoleh ukuran lebar bantal adalah $47,45 \mathrm{~cm}$ toleransi sebesar $4,7 \mathrm{~cm}$ ini dengan pertimbangan agar ibu lebih nyaman saat menyusui. dengan demikian rentang siku ke siku hampir subjek penelitian hampir sama dengan rentang siku ke siku di tempat lainnya di wilayah Bali. Penggunaan redesain bantal pada ibu menyusui di tempat penelitian dapat mengurangi keluhan setelah menyusui, ini berdasarkan wawancara didapat bahwa ibu menyusui merasakankenyamanan saat menggunakan bantal saat menyusui.

Berdasarkan hasil penelitian, dapat diketahui bahwa sebagian besar responden memiliki motivasi pemberian ASI yang tinggi yaitu 64,6\%, produksi ASI 64,6\%, dan musculoskeletal disorder $39,6 \%$ mengatakan tidak mengalami sakit.

Hal ini sesuai dengan teori bahwa motivasi adalah suatu dorongan yang terdapat dalam diri seseorang untuk berusaha memenuhi tujuan, kebutuhan, dalam upaya untuk menciptakan keseimbangan kehidupan seseorang yang diwujudkan dalam bentuk perilaku (Jama \& Asnaniar, 2020). Motivasi adalah daya dalam diri individu sebagai pendorong maupun penggerak yang melatarbelakangi individu untuk berperilaku dalam mencapai tujuan guna memenuhi kebutuhan psikis maupun fisiknya.

Pada penelitian ini sebagian besar responden memilik motivasi yang tinggi untuk memberikan ASI. Alasan ibu yang termotivasi dalam memberikan ASI adalah karena ibu menganggap bahwa pemberian ASI eksklusif merupakan sesuatu yang penting bagi dirinya (Jama \& Asnaniar, 2020). Seorang ibu yang secara sadar menilai dan memutuskan bahwa pemberian ASI eksklusif merupakan suatu tantangan bagi semua ibu menyusui yang bekerja untuk memberikan ASI dengan berbagai cara yang dapat dilakukan (Asih \& Nyimas, 2020).

Setiap ibu memiliki suatu kebutuhan psikologis yaitu salah satunya adalah kebutuhan kompetensi. Kebutuhan kompetensi merupakan kebutuhan yang melibatkan kemampuan ibu untuk melihat diri sendiri sebagai seseorang yang sepenuhnya mampu mendapatkan hasil yang diinginkan. Apabila ibu mendapatkan hasil yang diinginkannya, ibu akan menganggap dirinya lebih kompeten sehingga motivasi intrinsik yang dimiliki akan lebih besar dalam memberikan ASI (Lestari, et al., 2018).

Keinginan yang mendasari ibu dalam memberikan ASI antara lain adalah keinginan untuk memperkuat ikatan antara ibu dan bayi karena bekerja dapat memberikan jarak pada 
hubungan ibu dan bayi, keinginan ibu agar bayi lebih sehat daripada bayi yang diberikan susu formula sehingga ibu tidak harus mengambil cuti kerja karena bayinya yang sedang sakit.

Motivasi ibu dalam memberikan ASI eksklusif yaitu karena adanya rasa kepuasan atau kesenangan. Memberikan ASI dapat memberikan perasaan yang baik bagi ibu. Ibu dapat memberikan sesuatu yang tidak bisa diberikan oleh orang lain kepada bayinya.

Pada Ibu yang tidak bekerja atau ibu rumah tangga yang memberikan ASI eksklusif dapat menghemat pengeluaran untuk susu formula, perlengkapan menyusui dan persiapan pembuatan minum susu formula. Pemberian ASI juga menghemat pengeluaran untuk berobat bayi, misalnya biaya jasa dokter, biaya pembelian obatobatan, dan biaya perawatan bayi di rumah sakit .

Pemberian ASI lebih praktis karena dapat diberikan dimana saja dan kapan saja dalam keadaan segar, bebas bakteri, dalam suhu yang sesuai, tidak memerlukan peralatan khusus dalam penyajiannya dan selalu tersedia, sangat ekonomis sehingga dapat menghemat pengeluaran anggaran rumah tangga (Bahiyatun, 2007).

Motivasi dalam pemberian ASI eksklusif pada ibu yang diberikan hypnobreastfeeding dan edukasi laktasi juga didasari oleh keinginan memperoleh manfaat ASI. Ibu yang mengetahui kandungan dan manfaat ASI akan memiliki keinginan yang lebih tinggi dalam memberikan ASI eksklusif daripada pemberian susu formula, keinginan ibu untuk mendapatkan perhatian dari keluarga terutama suami, keinginan ibu untuk memperoleh manfaat ASI pada bayi, ibu, dan keluarga, keinginan ibu untuk meningkatkan hubungan kasih sayang dengan bayinya.

\section{Produksi ASI}

Berdasarkan hasil penelitian ini, produksi ASI dinilai dari tiga hal, yaitu persepsi ibu tentang produksi ASI, hasil observasi produksi ASI dengan melihat frekuensi BAK bayi, kenaikan berat badan bayi setelah usia 1 bulan. Berdasarkan analisis data diketahui bahwa sebagian besar yaitu $64,6 \%$ responden memiliki persepsi tentang produksi ASI dalam kategori baik, hasil observasi tentang produksi ASI dalam kategori baik, dan kenaikan berat badan bayi dalam kategori baik.

\section{Pengaruh Penggunaan Bantal Menyusui terhadap Motivasi Pemberian ASI}

Hasil penelitian yang telah dicapai adalah telah dilaksanakan kegiatan penelitian dengan memberikan bantal menyusui re-desain yaitu bantal dengan ukuran dan ketebalan yang di redesain dari bantal menyusui biasa menjadi bantal menyusui dengan spesifikasi bahan dasar spon (dacron), dilapisi perlak, ukuran bantal: diameter dalam $16 \mathrm{~cm}$, diameter luar $50 \mathrm{~cm}$, tinggi bantal awal adalah $12 \mathrm{~cm}$ di re-desain menjadi $22 \mathrm{~cm}$, dan berat bantal 1000gr. Bantal menyusui redsain ini diberikan kepada kelompok intervensi dan bantal menyusui biasa pada kelompok kontrol pada ibu menyusui hari pertama sampai dengan bayi berusia 1 bulan, kemudian di lakukan pengukuran motivasi, produksi ASI dan musculoskeletal disorder, dengan hasil penelitian terlampir. Kuesioner diberikan secara online kepada responden, sebelumnya diadakan kelas untuk memberikan sosialisasi cara pengisian kuesioner. Pada responden yang mengalami kesulitan dalam pengisian kuesioner, dipandu oleh enumerator yang bertugas di Praktik Mandiri Bidan tempat responden terbiasa mendapatkan pelayanan antenatal, intranatal dan postnatal care. Untuk musculoskeletal disorder dilakukan penilaian menggunakan nording body map oleh enumerator melalui lembar kuesioner.

Pengambilan data motivasi dan produksi ASI, serta muscululosceletal disorder telah dilaksanakan baik pada kelompok intervensi maupun kelompok kontrol telah selesai dilaksanakan dengan bantuan 8 orang bidan sebagai enumerator yang sudah dilakukan persamaan persepsi dan dilatih sebelumnya.

Berdasarkan hasil uji menggunakan Independent $T$ Test dapat diketahui bahwa ada perbedaan yang signifikan motivasi pemberian ASI, produksi ASI, dan musculoskeletal disorder antara ibu yang menyusui menggunakan bantal menyusui re-desain dengan ibu yang menyusui menggunakan bantal menyusui biasa.

Data motivasi ibu menyusui diukur berdasarkan skor dari kuesioner 30 item kelelahan (poin 11 sampai dengan 20). Dalam penelitian untuk variabel motivasi pengambilan data dilakukan pada kelompok kontrol dan bantal desain baru pada kelompok perlakuan. Data variabel motivasi dalam penelitian diuji normalitas dengan Shapiro-Wilk Test $(\mathrm{n}<50)$, menunjukan data berdistribusi normal ( $p$ value $>0,05)$. Sedangkan uji homogenitas terhadap variabel motivasi diujikan dengan levene's test untuk mengetahui homogenitas pada masingmasing kelompok. Uji komparabilitas motivasi antar kelompok kontrol maupun perlakuan ada perbedaan yang signifikan ( $p$-value $<0,05)$, dengan nilai $\mathrm{T}=0,01$ artinya ada perbedaan yang signifikan motivasi ibu pada kelompok kontrol dan kelompok perlakuan adalah sama. 
Motivasi adalah sesuatu yang mendorong atau mendorong seseorang bertingkah laku untuk mencapai tujuan tertentu. Berdasarkan hasil penelitian didapatkan bahwa rerata beda motivasi ibu kelompok kontrol 1,90 $\pm 0,530$ sedangkan rerata beda motivasi ibu kelompok perlakuan $3,09 \pm 1,044$. Perubahan motivasi ibu pada kedua kelompok bisa disebabkan karena penggunaan bantal menyusui membuat ibu merasa nyaman selama menyusui. Lama ibu menyusui bayinya rata-rata 20 sampai dengan 30 menit untuk masing-masing payudara, dengan jarak waktu antar menyusui kurang lebih dua sampai tiga jam, pada waktu ibu menyusui dengan menggunakan bantal menyusui tangan yang menyangah bayi akan ditopang oleh bantal sehingga terjadi peningkatan motivasi sebesar 3\%, penggunaan redesain bantal pada ibu menyusui dapat membuat posisi/sikap menyusui menjadi nyaman saat menyusui, sehingga mendorong ibu untuk menyusui lebih lama.

Penelitian tentang persepsi dan motivasi ibu tentang pemberian ASI yang dilakukan Fithri (2014)menunjukkan bahwa ada hubungan antara peserpsi dan motivasi ibu mengenai pemberian ASI kepada bayinya secara eksklusif pada masyarakat pedesaan menunjukan hasil 0,031 dapat diartikan bahwa persepsi dan motivasi ibu dalam menyusui bayi memberikan kontribusi sebesar $31 \%$ terhadap pemberian ASI secara eksklusif pada masyarakat di wilayah pedesaan

\section{Pengaruh Penggunaan Bantal Menyusui terhadap Produksi ASI}

Berdasarkan hasil analisis diperoleh hasil bahwa ada perbedaan yang signifikan produksi ASI antara ibu yang menyusui menggunakan bantal menyusui re-desain dengan ibu menyusui menggunakan bantal menyusui biasa dengan $p$ value 0,06 .

Produksi ASI pada penelitian ini dilihat dari variabel kepuasan bayi. Data diukur berdasarkan lembarobservasi bayi yang meliputi: berat bayi, kondisi bayi tertidur setelah menyusu, jumlah buang air kecil, jumlah buang air besar serta kondisi payudara. Pengambilan data untuk kepuasan bayi dilakukan satu hari setelah menyusui baik pada kelompok kontrol dan kelompok perlakuan. Uji normalitas menggunakan Shapiro-Wilk Test $(\mathrm{n}<50)$, menunjukan data berdistribusi normal ( $p$ value $>0,05)$. Sedangkan uji homogenitas terhadap variabel kepuasan bayi diujikan dengan levene's test untuk mengetahui homogenitas pada masing-masing kelompok, hasil analisis data motivasi normal (p-vale>0,05). Uji komparabilitas pada variabel kepuasan bayi dengan uji T-independent untuk mengetahui kondisi awal bayi antara kelompok kontrol dan perlakuan. Uji beda kepuasan bayi pada kelompok kontrol dan perlakuan, diuji menggunakan uji t-paired. Analisis kepuasan bayi menyusui menunjukan ada perbedaan bermakna karena nilai $p$-value lebih kecil dari $0,05$ (p-value $<0,05)$ hal ini berarti bahwa ada perbedaan kepuasan bayi padakelompok kontrol dan kelompok perlakuan. Adanya perbedaan peningkatan produksi ASI pada penggunaan bantal menyusui re-desain dibandingkan dengan bantal menyusui biasa adalah karena dengan penggunaan bantal menyusui yang tepat dapat memberikan posisi yang ergonomis ibu pada saat menyusui sehingga posisi dan perlekatan menyusui menjadi tepat dan menambah kenyamanan ibu menyusui. Ibu menyusui yang merasa nyaman dapat meningkatkan hormon prolaktin dan oksitosin sehingga produksi dan pengeluaran ASI menjadi lancar.

Kepada seluruh bidan untuk dapat merekomendasikan penggunaan bantal menyusui re-desain untuk meningkatkan kenyamanan pada ibu menyusui sehingga mempermudah mendapatkan posisi dan perlekatan menyusui yang tepat sehingga membantu tercapainya cakupan pemberian ASI eksklusif dan pemberian ASI hingga 2 tahun atau lebih.

\section{Pengaruh Penggunaan Bantal Menyusui terhadap MusculoskeletalDisorder}

Berdasarkan hasil analisis diketahui ada perbedaan yang signifikan musculoskeletal disorder pada ibu menyusui yang menggunakan bantal menyusui re-desain dengan ibu menyusui yang menggunakan bantal menyusui biasa dengan hasil uji T 0,01.

Data keluhan musculoskeletal ibu menyusui didapatkan berdasarkan skor dari kuesioner Nordic Body Map. Uji normalitas dengan Shapiro-Wilk Test $(\mathrm{n}<50)$, menunjukan data berdistribusi normal ( $p$-value $>0,05)$. Sedangkan uji homogenitas terhadap dengan levene's test hasil analisis data normal ( $p$ value $>0,05)$. uji komparabilitas menunjukan ada perbedaan ( $p$-value $<0,05)$, dengan nilai $\mathrm{T}=0,01$ artinya ada perbedaan yang signifikan antar dua kelompok perlakuan. Hasil penelitian ini sesuai dengan penelitian Muliarthini (2016) rata- rata sebelum menggunakan bantal menyusui adalah $37,54 \pm 1,694$.

Musculoskeletal Disorders (MSDs) yang dirasakan oleh ibu menyusui disebabkan oleh faktor-faktor yang dapat menimbukan 
ketidaknyamanan, salah satunya adalah ibu yang baru melahirkan pertama kali dan belum mngetahui teknik menyusui yang benar. Menurut Lismaysarah (2013), menyusui tidak semudah apa yang kita lihat dan memerlukan latihan terutama bagi para ibu muda yang baru pertama kali melahirkan seorang anak. Untuk belajar bagaimana cara memegang dan menyangga bayi, seorang ibu menyusui harus berada pada posisi yang nyaman, membutuhkan waktu, koordinasi serta kesabaran.

Penelitian yang dilakukan Rakhmadhany (2013) menunjukkan hasil ibu menyusui akan mengalami keluhan musculoskeletal sebesar 88,6\% yang dipengaruhi oleh faktor kesegaran jasmani ibu menyusui. Penelitian Adiatmika (2007) menyebutkan perbaikan kondisi kerja dengan pendekatan ergonomi total dapat menurunkan keluhan musculoskeletal sebesar $5,24 \%$. Pada penelitian yang dilakukan oleh Muliarthini (2016) tentang Penggunaan Redesain Bantal Menyusui Meningkatkan Motivasi Ibu Menyusui dan Kepuasan Bayi Serta Mengurangi Kelelahan dan Keluhan Musculoskeletal Ibu Post Partum didapatkan bahwa penggunaan bantal menyusui dapat mengurangi keluhan musculoskeletal pada ibu menyusui sebesar $6,36 \%$.

Penggunaan bantal menyusui dapat memberikan bantuan bagi posisi menyusui yang tepat. Bila ibu menempatkan bayi di atas bantal ibu menyusui, itu akan lebih nyaman untuk punggung, leher dan lengan. Bantal menyusui merupakan salah satu kunci keberhasilan program ASI dengan mendukung ibu dalam proses menyusui dengan memberi rasa nyaman pada ibu saat menyusui dan kepuasan pada bayi (Fitriani, 2017).

Hasil analisis keluhan musculoskeletal berdasarkan kuesioner nordic body map secara diskriptif dari 28 jenis pertanyaan tentang keluhan musculoskeletal pada ibu setelah menyusui, keluhan yang disampaikan oleh ibu setelah menyusui adalah berdasarkan pertanyaan: Sakit/kaku di leher atas, leher bawah, dibagian bahu kiri, bahu kanan, lengan atas kiri, lengan atas kanan, punggung, lengan bawah kiri, lengan bawah kanan.

Keluhan musculoskeletal adalah gangguan pada bagian otot skeletal yang disebabkan oleh karena otot menerima beban statis secara berulang dan terus menerus dalam jangka waktu yang lama Data keluhan musculoskelatel antar kelompok menunjukkan ada perbedaan bermakna ( $p$-value $>0,05)$, dengan $\mathrm{t}=7,546$ dan nilai $p$ value $=0,0001$, artinya ada perbedaan keluhan musculoskeletal.
Keluhan ini dirasakan mulai dari keluhan sangat ringan sampai sangat sakit, ini terjadi apabila otot menerima beban statis secara berulang dan dalam waktu yang lama. penggunaan desain baru bantal menyusui akan membuat posisi ibu yang nyaman saat menyusui, ini akan mengurangi peregangan otot saat menyusui sehingga dapat membantu ibu untuk menjaga kondisi fisik selama proses menyusui.

Penelitian yang dilakukan Rakhmadhany (2013) menunjukkan hasil ibu menyusui akan mengalami keluhan musculoskeletal sebesar 88,6\% yang dipengaruhi oleh faktor kesegaran jasmani ibu menyusui. Penelitian Adiatmika (2007) menyebutkan perbaikan konsidi kerja dengan pendekatan ergonomi total dapat menurunkan keluhan musculoskeletal sebesar 5,24\%.

Berdasarkan hasil penelitian, hasil analisis setelah melakukan re-desain bantal menyusui terjadi penurunan keluhan musculoskeletal sebesar 6,36\% dan perbedaan bermakna ( $p$ value $>0,05)$, dengan demikian dapat dikatakan bahwa penggunaan re-desain bantal menyusui yang mengacu pada aspek antropometri dengan menambah ketinggian bantalterbukti mengurangi keluhan musculoskeletal dan posisi menyusui menjadi nyaman. Hasil penelitian ini sesuai dengan penelitian yang dilakukan oleh Muliarthini (2016) didapatkan keluhan musculoskeletal pada kelompok kontrol adalah 37, 54ะ1,694.

Musculoskeletal Disorders (MSDs) merupakan ketidakseimbangan antara otot dan tulang karena aktivitas menyusui dilakukan ibu berulang-ulang setiap hari (Fitriani, 2017). Gangguan musculoskeletal adalahgangguan pada bagian otot rangka yang disebabkan karena otot menerima beban statis secara berulang dan terus menerus dalam jangka waktu yang lama dan akan menyebabkan keluhan pada sendi, ligamen dan tendon (Umami, et al., 2014).

Hasil penelitian terkait yang dilakukan oleh Fitriani (2017) tentangPengaruh Pemakaian Bantal menyusui Terhadap Kenyamanan Ibu dan Kepuasan Bayi dalam Proses Menyusui di Puskesmas Batua Makassar didapatkan bahwa sebanyak 20 ibu (100\%) merasa puas dan nyaman dengan memakai bantal menyusui selama menyusui.

Penggunaan bantal menyusui dapat memberikan bantuan bagi posisi menyusui yang tepat. Bila ibu menempatkan bayi di atas bantal ibu menyusui, itu akan lebih nyaman untuk punggung, leher dan lengan. Bantal menyusui atau bantal menyusui merupakan salah satu kunci keberhasilan program ASI dengan mendukung ibu dalam proses menyusui dengan memberi rasa nyaman pada ibu saat menyusui dan kepuasan 
pada bayi (Fitriani, 2017).

Penelitian ini sejalan dengan penelitian yang dilakukan oleh fitriani (2017) tentang Pengaruh Pemakaian Bantal menyusui Terhadap Kenyamanan Ibu dan Kepuasan Bayi Dalm Proses Menyusui di Puskesmas Batua Makassar. Uji statistik dengan korelasi Fisher's Exact diperoleh nilai $p$-value $=0,020$ ( $p$-value $<0,05$ ). Hal tersebut menunjukkan bahwa ada hubungan dan korelasi dengan pemakaian bantal menyusui terhadap kenyamanan ibu dalam proses menyusui.

Penelitian lain yang dilakukan Rakhmadhany (2013) menunjukkan hasil ibu menyusui akan mengalami keluhan musculoskeletal sebesar $88,6 \%$ yang dipengaruhi oleh faktor kesegaran jasmani ibu menyusui. Adiatmika (2007) yang menyebutkan perbaikan kondisi kerja dengan pendekatan ergonomi total dapat menurunkan keluhan musculoskeletal sebesar $5,24 \%$. Pada penelitian yang dilakukan oleh Muliarthini (2016) tentang Penggunaan Redesain Bantal Menyusui Meningkatkan Motivasi IbuMenyusui dan Kepuasan Bayi Serta Mengurangi Kelelahan dan Keluhan Musculoskeletal Ibu Post Partum didapatkan bahwa penggunaan bantal menyusui dapat mengurangi keluhan musculoskeletal pada ibu menyusui sebesar $6,36 \%$.

Dengan adanya penurunan ketidaknyamanan ini membuktikan bahwa penggunaan bantal menyusui dapat mengurangi Musculoskeletal Disorders (MSDs) yang dialami ketika ibu menyusui. Bantal menyusui merupakan pemanfaatan teknologi tepat guna yang digunakan untuk mengurangi rasa ketidaknyamanan ibu ketika menyusui akibat teknik menyusui yang kurang tepat dan lamanya proses menyusui.

\section{SIMPULAN}

Berdasarkan hasil penelitian dapat disimpulkan bahwa ada perbedaan yang signifikan motivasi pemberian ASI, Produksi ASI dan musculoskeletal disorder antara ibu menyusui menggunakan bantal menyusui redesain dan ibu menyusui menggunakan bantal menyusui biasa. Sebagian besar responden memiliki motivasi pemberian ASI dan produksi ASI yang tinggi, serta musculoskeletal disorder dalam kategori tidak sakit.

Ada perbedaan yang signifikan motivasi pemberian ASI, Produksi ASI, musculoskeletal disorder antara kelompok ibu yang menggunakan bantal menyusui re-desain dengan kelompok ibu yang menggunakan bantal menyusui biasa.

Selanjutnya rekomendasi yang dapat saya berikan setelah melakukan penelitian ini diantaranya pada ibu menyusui untuk dapat menggunakan bantal menyusui sehingga dapat menambah kenyamanan proses menyusui dan mendapatkan posisi dan perlekatan menyusui yang tepat sehingga motivasi dan produksi ASI dapat meningkat serta meminimalisir keluhan musculoskeletal disorder. Bagi tempat penelitian, agar bidan PMB dan Bidan Puskesmas untuk dapat menyediakan bantal menyusui re-desain sehingga dapat membantu ibu menyusui menyusui bayinya dengan posisi dan perlekatan yang benar. Bagi institusi pendidikan terutama jurusan kebidanan, untuk dapat menjadikan hasil penelitian sebagai pembaharuan bahan ajar terutama mata kuliah askeb nifas dan menyusui. Bagi peneliti lain, agar dapat melaksanakan penelitian denga menentukan variabel independen lain yang dapat berpengaruh pada motivasi dan produksi ASI dan meningkatkan kenyamanan ibu menyusui serta meminimalisir musculoskeletal disorder pada ibu menyusui. Diharapkan dapat melakukan penelitian mengenai penggunaan bantal menyusui dengan sampel yang lebih homogen dan perlu kajian lebih lanjut untuk waktu intervensi penelitian.

\section{DAFTAR PUSTAKA}

Adiatmika, I., Manuaba, A., Adiputra, N., \& Sutjana, D. (2007). Perbaikan Kondisi Kerja Dengan Pendekatan Ergonomi Total Menurunkan Keluhan Musculoskeletal Dan Kelelahan Serta Meningkatkan Produktivitas Dan Penghasilan Perajin Pengecatan Logam Di Kediri-Tabanan. Indonesian Journal of Biomedical Sciences, 1(3), 1-12.

Amalia, R., \& Rizki, L. K. (2018). Faktor Faktor Yang Mempengaruhi Keberhasilan Ibu Bekerja Dalam Pemberian Asi Eksklusif. Mandala Of Health, 11(1), 44. https://doi.org/10.20884/1.mandala.2018.1 1.1 .546

Amir, Aswita, Rowa, S. S., \& Islamiyah, N. (2020). Edukasi Dengan Media Leaflet Terhadap Posisi Dan Perlekatan Pada Bayi Saat 
Menyusu. Media Gizi Pangan, 27(1), 22-28.

Asih, Y., \& Nyimas, A. (2020). Hypnobreastfeeding to increase motivation and breast milk production: A study. International Journal of Innovation, Creativity and Change, 13(2).

Bahiyatun. 2009. Buku Ajar asuhan Kebidanan Nifas normal. Jakata: EGC.

Bobak. (2005). Buku ajar keperawatan. Edisi 4. Jakarta: EGC.

Fitriani. (2017). Pengaruh Pemakaian Breastfeeding Pillow Terhadap Kenyamanan Ibu dan Kepuasan Bayi Dalam Proses Menyusui Di Puskesmas Batua Makassar. Jurnal Mitrasehat, VII(2), 215-222.

Fithri, H. (2017). Hubungan Motivasi dengan Riwayat Pemberian ASI Eksklusif pada Ibu yang Bekerja di Perusahaan Wilayah Kabupaten Bantul. [Skripsi]. Yogyakarta: Fakultas Ilmu-ilmu Kesehatan, Universitas Alma Ata Yogyakarta.

Grandjean, E., \& Kroemer, K. H. (1997). Fitting the task to the human: a textbook of occupational ergonomics. CRC press.

Jama, F., \& Asnaniar, W. O. S. (2020). Pelatihan Pijat Oksitosin Untuk Meningkatkan Cakupan ASI Eksklusif. Window of Community Dedication Journal, 1(1), 2127. https://doi.org/10.33096/wocd.vi.30

Lestari, P. P., Astuti, D. A., \& Nurdiati, D. S. (2018). Pengaruh Dukungan Sosial Pada Keberhasilan Menyusui di RSUD Panembahan Senopati Kabuaten Bantul. Prosiding Konferensi Nasional Ke- 7, 74-77.

Lismaysarah, M. (2013). Hubungan tehnik menyusui dengan kelancaran asi pada ibu menyusui di wilayah kerja puskesmas Blang Bintang Aceh besar. Jurnal Publikasi Kesehatan. http://simtakp. uui. ac.id/docjurnal/MONA_LISMAYSARAHjurnal. pdf.

Moore, E. R., Coty, M.B. (2006). Prenatal and postpartum focus groups with primiparas: breastfeeding attitudes, support, barriers, self-efficacy, and intention. Journal Pediatrics Health Care 20, 35-46.

Muliarthini, N. W., Sutjana, I. D. P., \& Adiatmika, I. P. G. (2016). Penggunaan redesain bantal menyusui meningkatkan motivasi ibu menyusui dan kepuasan bayi serta mengurangi kelelahan dan keluhan muskuloskeletal ibu post partum. Jurnal Ergonomi Indonesia, 2(2), 27-40.

Nisman, W. A., Parmawati, I., Wismawati, P.,
Fitriana, N., \& Maharani, F. (2020). How Do Breastfeeding Pillows Influence Mother Fatigue and Mother and Baby Response During Breastfeeding? Indian Journal of Public Health Research \& Development, 11(8), 344-350. https://doi.org/10.37506/ijphrd.v11i8.10946

Purnomo, H., Manuaba, A., \& Adiputra, N. (2007). Sistem Kerja Dengan Pendekatan Ergonomi Total Mengurangi Keluhan Muskuloskeletal, Kelelahan Dan Beban Kerja Serta Meningkatkan Produktivitas Pekerja Industri Gerabah Di Kasongan, Bantul. Indonesian Journal of Biomedical Sciences, 1(3).

Prawirohardjo, Sarwono. (2008). Ilmu Kebidanan. Jakarta: Yayasan Bina Pustaka.

Presiden Republik Indonesia. (2012). Peraturan Pemerintah Republik Indonesia nomor 33 tahun 2012 tentang pemberian air susu ibu eksklusif. Lembaran Negara RI Tahun 2012.

Prihantara D.F. (2012). Perancangan Alat Bantu Menyusui Dengan Pendekatan Ergonomi Menggunakan Metode Quality Function Deploment. [Tugas Akhir]. Bandung: Institut Teknolagi Telkom.

Rakhmadhany, Titi. (2013). Faktor- faktor yang Berhubungan dengan Keluhan Musculoskeletal Disorders pada Ibu Menyusui Bayi dengan Usia 0 sampai 6 Bulan di Kelurahan Pisangan Ciputat Timur. [Skripsi]. Jakarta: Fakultas Ilmu Kesehatan, UIN Syarif Hidayatullah Jakarta.

Roberts, D. (2011). Preventing Musculoskeletal Pain in Mothers Ergonomic Tips for Lactation Consultants. Clinical Lactation, 2(4), 13-20.

Santiana, I. M. A., Yusuf, M., \& Sutapa, I. N. (2017). Desain Kursi Ergonomis Ibu Menyusui Menurunkan Keluhan Otot Dan Meningkatkan Motivasi Pemberian Asi Eksklusif. Jurnal Ergonomi Indonesia (The Indonesian Journal of Ergonomic), 3(2), 27-33.

https://doi.org/10.24843/jei.2017.v03.i02.p04

Umami, dkk. (2014). Hubungan antara Karakteristik Responden dan Sikap Kerja Duduk dengan Keluhan Nyeri Punggung Bawah (Low Back Pain) Pada Pekerja Batik Tulis. e-Jurnal Pustaka Kesehatan, 2(1).

Wardani, L. K. (2003). Evaluasi ergonomi dalam perancangan desain. Dimensi Interior, 1(1), 61-73. 